\title{
Blurred vision and high blood pressure in a young woman
}

\author{
D E H Flanagan, C Cole, M D P Crick, D Kerr
}

\begin{abstract}
Summary
A 41-year-old woman presented with a short history of blurred vision. She had a 6-year history of refractory hypertension which had been treated with a variety of drug regimens. She was found to have bilateral branch retinal vein occlusion. Retinal vein occlusion is a recognised complication of hypertension but simultaneous involvement of both eyes is extremely rare. Following this episode, blood pressure control has improved without change in drug therapy, suggesting that treatment compliance may partly explain the previous difficulties.
\end{abstract}

Keywords: retinal vein occlusion; hypertension

A 41-year-old woman presented with a 9-day history of blurred vision. Six years earlier, immediately following the birth of her second child, she developed hypertension. Investigations at that time, including creatinine clearance, renal angiography, multiple urinary catecholamines measurements, urine microscopy and autoimmune profile, did not show any evidence of secondary causes for her raised blood pressure. In addition, there was a family history of hypertension affecting her father, mother and sister. Two family members had suffered subarachnoid haemorrhages. Over the years a number of drug regimens had been used with limited success in controlling her

MRC Environmental Epidemiology Unit, blood pressure with casual recordings consist-

Southampton General Hospital,

Southampton, UK

D E H Flanagan

Metabolism Unit, Royal Bournemouth Hospital,

Bournemouth, Dorset BH7 7DW, UK

C Cole

D Kerr

Royal Victoria

Hospital, Westbourne, Bournemouth, Dorset, UK

M D P Crick

Correspondence to Dr Kerr

Accepted 10 March 1998

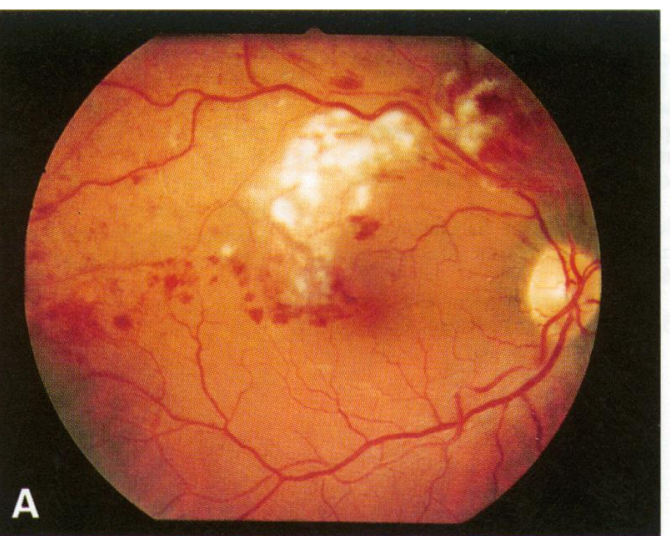
clearly visible in both eyes ently greater than $160 / 90 \mathrm{mmHg}$. These included combinations of atenolol, celiprolol, bendrofluazide, frusemide, nifedipine, amlodipine, enalapril, lisinopril, ramipril, methyldopa, prazosin, doxazosin, minoxidil, guanethidine and bethanidine. Understandably she found the drug regimens difficult to follow. The blood pressure tended to improve during hospital admissions, raising the question of poor compliance. At the time of deterioration in her vision she was taking ramipril $5 \mathrm{mg}$ bid, propranolol $160 \mathrm{mg}$ bid, frusemide $40 \mathrm{mg}$ daily, debrisoquine $10 \mathrm{mg}$ bid and aspirin 75 $\mathrm{mg}$ daily. She was a smoker of 15 cigarettes a day for many years; she was overweight at $75 \mathrm{~kg}$ with a body mass index of $29 \mathrm{~kg} / \mathrm{m}^{2}$. Lipid profile was normal.

On examination, blood pressure was 230/ $140 \mathrm{mmHg}$. Visual acuity was $6 / 6$ in the left eye and $6 / 9$ in the right eye. Retinal examination showed bilateral upper temporal branch retinal vein occlusions with cotton wool spots (figure). On formal visual field testing she had a bilateral inferior field loss which was worse on the right. On admission to hospital, on her usual treatment, blood pressure improved to $140 / 90 \mathrm{mmHg}$. Investigations including autoimmune profile, full blood count and erythrocyte sedimentation rate, clotting profile and lupus anticoagulant were normal. Over time acuity improved to $6 / 6$ in both eyes with improvement in visual fields. She has subsequently undergone bilateral laser ablation therapy.

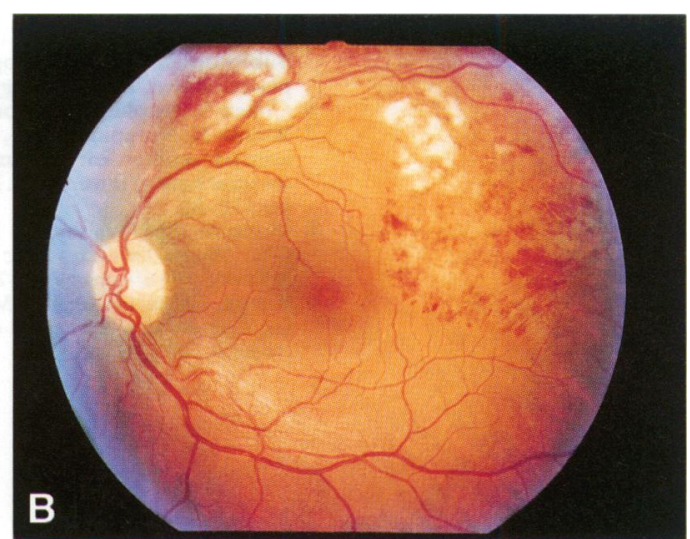

B

Figure Retinal photographs showing upper temporal retinal vein occlusion in both eyes. In the right eye (A) this encroaches on the fovea centralis explaining the deterioration in acuity in that eye. Hypertensive changes are also 


\section{Summary points}

- hypertension is the most common risk factor for retinal vein occlusion

- bilateral presentation is rare

- other risk factors include male gender and the recognised risk factors for vascular disease

- retinal vein occlusion is also associated with disorders of clotting function such as the anticardiolipin syndrome

- the sudden deterioration in vision may have emphasised the importance of drug compliance in this subject, as blood pressure control has subsequently improved

\section{Discussion}

Following a single episode of branched retinal vein occlusion (BRVO), subsequent involvement of the other eye is well recognised. ${ }^{1}$ However, simultaneous involvement of both eyes is

1 Pollack A, Dottan S, Oliver M. The fellow eye in retinal vein occlusive disease. Ophthalmology 1989;96:842-5.

2 Tewari HK, Khosla A, Khosla PK, Kumar A. Bilateral branch vein occlusion. Acta Ophthalmol 1992;70:278-80.

3 The Eye Disease Case-control Study Group. Risk factors for branch retinal vein occlusion. Am $\mathcal{F}$ Ophthalmol 1993;116: 286-96. extremely unusual. ${ }^{2}$ The most common risk factor for BRVO is hypertension with up to $50 \%$ of cases occurring in hypertensive individuals. ${ }^{3}$ Race, diabetes, obesity, male gender, hyperopia, and a history of coronary vascular disease or stroke are less strongly associated. ${ }^{4}$ The risk of BRVO decreases with alcohol consumption and high-density lipoprotein cholesterol. BRVO is also associated with disorders of clotting function including the anticardiolipin syndrome and Waldenstrom's macroglobulinaemia. ${ }^{5}$

This case highlights the eternal problem in managing hypertension. The patient has to persist with long-term treatment, often with unpleasant side-effects, without immediate apparent health gain. In this case it may be that the dramatic deterioration in vision personally emphasised the importance of controlling blood pressure. Certainly our patient's blood pressure control has improved without change in treatment since the event.

4 Johnston RL, Brucker AJ, Steinmann W, Hoffman ME, Holmes JH. Risk factors of branch retinal vein occlusion. Arch Ophthalmol 1985;103:1831-2.

5 Lureau MA, Glacet-Bernard A, Coscas G. Bilateral central retinal vein occlusion and circulating anticoagulant. [French]. $\mathcal{F}$ Fr Ophtalmol 1995;18:468-72. 